\title{
Occurrence of rheumatoid arthritis is not increased in the first degree relatives of a population based inception cohort of inflammatory polyarthritis
}

\author{
M A Jones, A J Silman, S Whiting, E M Barrett, D P M Symmons
}

\begin{abstract}
Objective-To determine the risk of rheumatoid arthritis (RA) in first degree relatives of a true population based sample of probands with inflammatory polyarthritis.

Methods-In a case-control study, a two stage screening procedure was used to ascertain the prevalence of RA in $\mathbf{5 1 8}$ first degree relatives of 207 Norfolk Arthritis Register cases registered in 1990 and 414 first degree relatives of 180 local controls. An initial joint symptom and medical history questionnaire was followed by a physical examination, and serological and radiological evaluation of those with symptoms.

Results-The prevalence of RA in the first degree relatives of all the Norfolk Arthritis Register cases was $7 \cdot 7 / 1000$, compared with $4 \cdot 8 / 1000$ in the first degree relatives of the controls, with a risk ratio of $1.6(95 \%$ confidence interval 0.3 to $8 \cdot 7$ ). This very modest increase was also seen when the analysis was restricted to the first degree relatives of Norfolk Arthritis Register cases who satisfied the American Rheumatism Association criteria for RA: prevalence rate $7 \cdot 2 / 1000$.
\end{abstract}

Conclusion-There was no evidence of an important increased familial risk of RA in this community based sample. These data are compatible with others from immunogenetic studies showing only weak HLA associations with community ascertained RA.

(Ann Rheum Dis 1996; 55: 89-93)

The clustering of any disease within families, at a frequency greater than the expected occurrence based on population prevalence, indicates that shared genetic or environmental factors (or a combination of both) are important in the aetiology of that disease. With regards to rheumatoid arthritis (RA), an increased disease concordance in monozygotic, compared with dizygotic, twins ${ }^{1-3}$ provides strong evidence of a genetic contribution to the disease. Detailed analysis of concordance within different types of relative pairs has suggested that RA is a polygenic disease with perhaps one major locus and a number of polygenes operating. ${ }^{4}$

Studies of genetic markers such as the HLA complex have been of fundamental importance in distinguishing between shared environment and shared genes as the explanation for familial clustering in RA. ${ }^{5-7}$ However, there is still a role for classical studies of familial clustering in quantifying the contribution of specific loci to the overall genetic susceptibility. Thus Risch ${ }^{8}$ has demonstrated a mathematical relationship between haplotype sharing at a particular locus for relative pairs and the familial recurrence risk. For multiple sclerosis he estimated, from the published sibling recurrence risk of 20 , that only $12 \cdot 5 \%$ of the genetic susceptibility could be explained by genes within the HLA region.

There are remarkably few data on the recurrence risk in first degree relatives of $R A$ probands. A number of studies of hospital or clinic probands have shown high proportions with an affected relative. ${ }^{9}{ }^{10}$ Such studies might over-represent those with familial disease for two reasons. First, genetic factors may code for severity rather than susceptibility, and so the apparently high frequency of familial cases in hospital attenders might be explained on the basis that they have more severe disease. Second, it is possible that those who develop symptoms similar to those of an affected relative are more likely to seek medical attention and be referred hospital.

The optimal approach to measurement of familial recurrence risk is to study the first degree relatives of population derived incident cases, and to compare their frequency of disease with that of the first degree relatives of a control population. There have been few such studies. A report from the Mayo clinic based on clinic ascertained cases arising within the Olmsted County population estimated that the age and gender adjusted incidence of RA in the first degree relatives of 78 probands with RA was 1.7 (95\% confidence interval (CI) 1.0 to 2.9 ) times that of the local population. ${ }^{11}$ Two reports, both from more than 25 years ago, also suggested a modestly increased risk in the first degree relatives of population derived prevalent cases. In an English study, ${ }^{12}$ the increased risk in first degree relatives was 1.2 $(95 \%$ CI 0.5 to 3.6$)$ and in a Swedish study ${ }^{13}$ the relative risk was $2 \cdot 4(95 \%$ CI 0.8 to $6 \cdot 8)$. In both studies, the probands were existing 
cases detected from a cross-sectional prevalence survey. Such surveys miss those with disease that went into remission. If genetic factors code for disease persistence rather than susceptibility, then the study of such patients would again overestimate familial occurrence.

We have examined the hypothesis that, in unselected incident cases of RA arising within a population, there is no evidence of substantial familial clustering.

\section{Subjects and methods}

DESIGN

A case-control design was used to compare the cumulative prevalence of RA in first degree relatives of case probands with that of an age and gender matched series of non-RA individuals selected from the same population.

\section{CASES}

The Norfolk Arthritis Register is a unique population based incidence register of inflammatory joint disease. It aims to ascertain all cases of inflammatory polyarthritis who seek care from a general practitioner within the Norwich Health Authority (NHA). In brief, the aim is to recruit all attenders at general practice with swelling of two or more joints. The patients are interviewed, examined and have blood taken for rheumatoid factor (RF) analysis. They are followed up annually. Details of the recruitment process have been published elsewhere. ${ }^{14}$ All cases notified in 1990 were included in this family study and, for the purpose of analysis, were subdivided into those who satisfied the 1987 American Rheumatism Association (ARA) criteria for $\mathrm{RA}^{15}$ at first visit or at the first annual follow up, or both, and those who did not satisfy the criteria on either occasion. Cases with another diagnosis, made by a hospital consultant, were excluded.

\section{CONTROLS}

The controls came from two sources: friends of the cases, matched for gender and age (within five years), without RA, living within the NHA area; and similarly age and gender matched subjects without RA, chosen from the age/ gender register of the case's general practitioner. The aim was to obtain at least one control per case from either source.

FIRST DEGREE RELATIVES

Each case and control was asked to provide a family tree giving the name, address, and date of birth of all living first degree relatives. All family members aged 16 or over and living within the NHA were eligible for study. Family trees were provided by 207 Norfolk Arthritis Register cases, detailing 749 first degree relatives of whom $593(79 \%)$ responded to an initial questionnaire. Of these, 64 lived outside the NHA, one was younger than 16 years, and 10 refused contact with the general practitioner, leaving 518 eligible for study.
Similarly, control family trees were available for 180 individuals, detailing 584 first degree relatives of whom $469(80 \%)$ responded. Of these, 42 lived outside the NHA and 13 were under 16 years of age, leaving 414 eligible for study.

ASCERTAINMENT OF RA STATUS IN FIRST DEGREE RELATIVES

A two stage screening technique was used. All first degree relatives were sent a postal questionnaire asking about current or past swelling in at least two joint groups, and diagnosis 'ever' by a physician of either RA or arthritis 'type unspecified'. This screening questionnaire has been shown to be $100 \%$ sensitive in detecting RA in other surveys. ${ }^{16}$ All positive responders were invited to have a detailed joint examination at home and to provide blood for RF estimation. In addition, the subject's general practitioner was contacted for details of previous findings and laboratory and radiographic results. In those individuals without previous radiographic results, and in whom radiographs were necessary to achieve accurate classification, new films of the hands and feet were requested.

ANALYSIS

The presence of RA in the first degree relatives was classified according to the 1987 ARA criteria, ${ }^{15}$ modified for population studies. ${ }^{17}$ In a study such as this, it is not always possible to establish with confidence whether a subject who does not have currently active disease can be classified as having RA, especially when contemporary medical records are incomplete. The cases of RA were therefore subdivided into those that were 'confirmed' (that is, satisfied the criteria) and those that were 'unconfirmed' because not all the required data were available.

The cumulative prevalence of RA was calculated for both case and control first degree relatives and the risk ratio of the prevalences calculated together with its $95 \%$ confidence interval. Separate subgroup analyses were undertaken for the first degree relatives of cases who satisfied the ARA criteria and those who did not. Initially, the analysis was performed separately for the first degree relatives of the friend and the general practitioner controls. However, as they did not differ in their frequency of RA, the data were pooled.

\section{Results}

The age distribution of the first degree relatives of the cases and controls was similar. The mean age of the case first degree relatives was 46 (SD 15) years, and that of the control first degree relatives 50 (14). Subsequent analyses were therefore not adjusted for age. More of the first degree relatives of cases were women compared with the first degree relatives of controls: $240(46 \%) v 165(40 \%)$. The data were analysed for both genders combined and each gender separately. Table 1 and the figure 
Table 1 Prevalence of rheumatoid arthritis in first degree relatives (FDR) of all cases with inflammatory polyarthritis and their controls

\begin{tabular}{|c|c|c|c|c|c|c|}
\hline & \multicolumn{3}{|c|}{ Case FDR } & \multicolumn{3}{|l|}{ Control FDR } \\
\hline & Men & Women & All & Men & Women & All \\
\hline $\begin{array}{l}\text { Number } \\
\text { Number with }\end{array}$ & 240 & .278 & 518 & 165 & 249 & 414 \\
\hline $\begin{array}{r}\text { confirmed RA } \\
\text { Prevalence/1000 }\end{array}$ & $\underline{0}$ & $\begin{array}{c}4 \\
14 \cdot 4 \\
(3 \cdot 9 \text { to } 36 \cdot 8)\end{array}$ & $\begin{array}{c}4 \\
7 \cdot 7 \\
(2 \cdot 1 \text { to } 19 \cdot 8)\end{array}$ & $\underline{0}$ & $\begin{array}{l}2 \\
8 \cdot 0 \\
(1 \cdot 0 \text { to } 29 \cdot 0)\end{array}$ & $\begin{array}{c}2 \\
4 \cdot 8 \\
(0.6 \text { to } 17 \cdot 4)\end{array}$ \\
\hline $\begin{array}{l}\text { Number with } \\
\text { confirmed and } \\
\text { non-confirmed RA } \\
\text { Prevalence/ } 1000\end{array}$ & $\underline{0}$ & $\begin{array}{l}7 \\
25 \cdot 2 \\
(10 \cdot 1 \text { to } 51 \cdot 9)\end{array}$ & $\begin{array}{c}7 \\
13 \cdot 5 \\
(5 \cdot 4 \text { to } 27 \cdot 8)\end{array}$ & $\begin{array}{c}2 \\
12 \cdot 1 \\
(1 \cdot 5 \text { to } 43 \cdot 8)\end{array}$ & $\begin{array}{l}3 \\
12 \cdot 0 \\
(2 \cdot 5 \text { to } 35 \cdot 2)\end{array}$ & $\begin{array}{c}5 \\
12 \cdot 1 \\
(3 \cdot 9 \text { to } 28 \cdot 2)\end{array}$ \\
\hline
\end{tabular}

Values in parentheses are $95 \%$ confidence intervals.

summarise the results. Overall $2.9 \%$ of the cases and $2 \cdot 2 \%$ of the controls had a first degree relative with confirmed or unconfirmed RA. The prevalence of confirmed RA in the first degree relatives of cases was $7 \cdot 7 / 1000,1.6$ times (95\% CI 0.3 to $8 \cdot 7$ ) that in the first degree relatives of controls. When both confirmed and unconfirmed RA were included, the prevalences were almost identical. There were no male first degree relatives with confirmed RA in either group, and the analysis restricted to women showed the same pattern as that for the group as a whole. Although the confidence intervals were wide (figure), the prevalence risk ratios were all between 1 and 2 .

The data were also examined restricting the analysis to those cases who were classified as having RA: 134 (65\%) of the 207 Norfolk Arthritis Register probands satisfied the ARA criteria by the end of one year. The overall prevalence of confirmed RA among the first

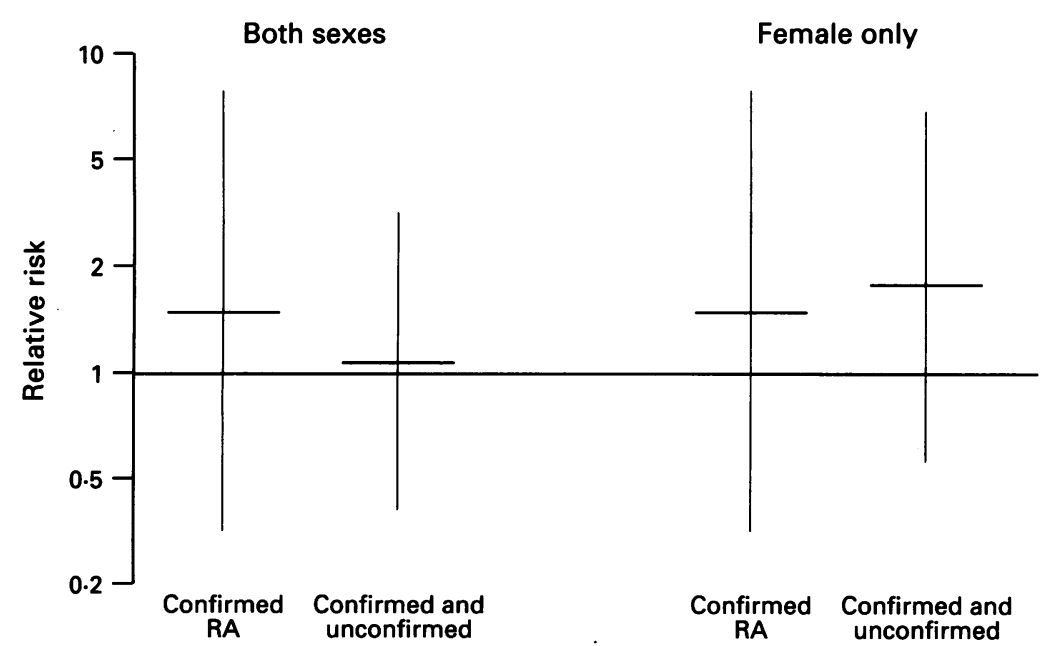

Relative risk of rheumatoid arthritis $(R A)$ in first degree relatives: cases versus controls. degree relatives of these cases was $7 \cdot 2 / 1000$ (relative risk $=2 \cdot 2,95 \% \mathrm{CI} 0 \cdot 2$ to 20.6 ) and that of confirmed plus unconfirmed RA was $12 \cdot 0 / 1000$ (table 2) - virtually identical to the results using the entire case dataset.

As an indicator of completeness of case ascertainment among the first degree relatives, we attempted to estimate the number of cases that would be expected on the basis of published data. There are no contemporary robust UK age specific prevalence data for both genders, from which to estimate expected numbers of RA cases. We therefore used age and gender specific data from the USA ${ }^{18}$ and applied them using 10 year age bands. (Published all-age prevalence rates for RA are remarkably similar for all Anglo-Saxon populations. ${ }^{19}$ ) Using these data, $7 \cdot 14$ individuals with RA would have been expected among the first degree relatives of the cases, compared with the seven observed (table 1), and 5.48 individuals with RA would have been expected among the first degree relatives of the controls, compared with five observed.

\section{Discussion}

This study has failed to demonstrate any important increased familial risk over background population risk among the first degree relatives of 'community' ascertained incident cases of inflammatory polyarthritis, independent of whether or not the case satisfied standard criteria for RA. These data confirm the low familial aggregation observed in other studies of population derived probands with $\mathrm{RA}^{11-13}$ (table 3 ).

Pooling the data from previous studies with the current data suggests a recurrence risk in first degree relatives of about 2-similar to the increase found in the present study with a 95\% confidence interval just excluding unity

Table 2 Prevalence of rheumatoid arthritis in first degree relatives (FDR) of all cases with confirmed $R A$ at one year and their controls

\begin{tabular}{|c|c|c|c|c|c|c|}
\hline & \multicolumn{3}{|c|}{ Case FDR } & \multicolumn{3}{|l|}{ Control FDR } \\
\hline & Men & Women & $A l l$ & Men & Women & All \\
\hline $\begin{array}{l}\text { Number } \\
\text { Number with }\end{array}$ & 200 & 218 & 418 & 123 & 177 & 300 \\
\hline $\begin{array}{r}\text { confirmed RA } \\
\text { Prevalence/1000 }\end{array}$ & $\underline{0}$ & $\begin{array}{l}3 \\
13 \cdot 8 \\
(2 \cdot 8 \text { to } 40 \cdot 2)\end{array}$ & $\begin{array}{l}3 \\
7 \cdot 2 \\
(1 \cdot 5 \text { to } 21 \cdot 0)\end{array}$ & - & $\begin{array}{c}1 \\
5 \cdot 6 \\
(0 \cdot 1 \text { to } 31 \cdot 5)\end{array}$ & $\begin{array}{c}1 \\
3 \cdot 3 \\
(0 \cdot 0 \text { to } 18 \cdot 6)\end{array}$ \\
\hline $\begin{array}{l}\text { Number with } \\
\text { confirmed and } \\
\text { non-confirmed RA } \\
\text { Prevalence/1000 }\end{array}$ & $\underline{0}$ & $\begin{array}{c}5 \\
22 \cdot 9 \\
(7 \cdot 4 \text { to } 53 \cdot 5)\end{array}$ & $\begin{array}{l}5 \\
12 \cdot 0 \\
(3.9 \text { to } 27.9)\end{array}$ & $\begin{array}{l}2 \\
16 \cdot 3 \\
(2 \cdot 0 \text { to } 58 \cdot 7)\end{array}$ & $\begin{array}{l}2 \\
11 \cdot 3 \\
(1 \cdot 4 \text { to } 40 \cdot 8)\end{array}$ & $\begin{array}{c}4 \\
13 \cdot 3 \\
\text { (3.6 to } 33 \cdot 8)\end{array}$ \\
\hline
\end{tabular}

Values in parentheses are $95 \%$ confidence intervals. 
Table 3 Population based studies of familial aggregation of $R A$

\begin{tabular}{|c|c|c|c|c|c|c|c|}
\hline Source & Year & $\begin{array}{l}\text { No of } R A \\
\text { probands }\end{array}$ & $\begin{array}{l}\text { No of } \\
\text { FDR }\end{array}$ & $\begin{array}{l}\text { No with } \\
R A\end{array}$ & Control group & $\begin{array}{l}\text { Estimate of risk } \\
(95 \% C I)\end{array}$ & Comments \\
\hline Lawrence $^{11}$ & 1969 & Not Stated & 145 & 9 & $\begin{array}{l}\text { Expected prevalence from } \\
\text { population }\end{array}$ & $1.2(0.5$ to 3.6$)$ & \\
\hline Hellgren $^{12}$ & 1970 & Not Stated & 444 & 12 & $\begin{array}{l}\text { FDR of age and gender } \\
\text { matched controls }\end{array}$ & $2.4(0.9$ to 7.0$)$ & $\begin{array}{l}\text { FDR matched for relationship } \\
\text { to proband. RA status } \\
\text { established from population } \\
\text { survey }\end{array}$ \\
\hline del Junco ${ }^{13}$ & 1984 & 78 & 496 & 15 & Population of Rochester & $1.7(1.0$ to 2.9$)$ & Comparison of incidence of \\
\hline & 1995 & 134 & 418 & $\begin{array}{l}3^{\star} \\
5 \dagger\end{array}$ & $\begin{array}{l}\text { FDR of age and gender } \\
\text { matched controls }\end{array}$ & $\begin{array}{l}2 \cdot 2(0.2 \text { to } 20 \cdot 6) \\
0.9(0 \cdot 2 \text { to } 3 \cdot 3)\end{array}$ & $\begin{array}{l}\text { RA status established by two } \\
\text { stage screening }\end{array}$ \\
\hline All studies combined & & & 1503 & $39 \ddagger$ & & $1 \cdot 9(1 \cdot 1$ to $3 \cdot 2)$ & $\begin{array}{l}\text { Meta analysis weighted } \\
\text { according to size of each } \\
\text { study }\end{array}$ \\
\hline
\end{tabular}

^The three cases were confirmed RA only; †The five cases were confirmed and unconfirmed RA; $¥$ The 39 cases were all confirmed RA

FDR $=$ First degree relatives.

(table 3). The lack of any major increased risk is also in keeping with the absence of any important association between HLA-DRB1 alleles and RA in cases ascertained either by community based prevalence surveys ${ }^{20}$ or from studies of incident cases. ${ }^{21} 22$

There are a number of important reservations that should be borne in mind in interpreting these data. First, the numbers of first degree relatives studied were small and, given low frequency of RA, the study had insufficient power to exclude an important effect. Nonetheless, even at the upper limit of the $95 \%$ confidence interval $(3 \cdot 5)$, the excess risk was substantially lower than for other HLA associated diseases such as insulin dependent diabetes $^{23}$ and multiple sclerosis. ${ }^{24}$

Second, the control first degree relatives were derived from two sources: friend controls and general practice controls. This should not have introduced any bias, as it was the first degree relatives rather than the controls themselves that were studied. It seems unlikely that either method of control selection would have resulted in a bias towards either a greater or lesser occurrence of RA in the first degree relatives. Further, the data from the two control groups were not different, suggesting that the aim of recruiting a representative local population group had been achieved. There was a small difference in the age distribution between the first degree relatives of the cases and the controls, but insufficient to have introduced any important differing risk.

Third, there may be a concern that underascertainment of disease may have resulted from the particular survey method, perhaps as a result of problems in recall. However, if any underascertainment was non-random, it is likely that it would have been biased towards 'better' recall by the first degree relatives of the cases, biasing the prevalence ratio above unity. Interestingly, when the US prevalence rates were applied, the expected numbers of RA relatives in the first degree relatives of both the cases and the controls were very close to those observed. These age and gender specific estimates are based on older data that might not be appropriate to the contemporary UK population. Nonetheless, these results suggest no important underascertainment of cases in the first degree relatives of the controls, and support the absence of an important increased risk in the first degree relatives of the cases.
The case probands in this study displayed a wide range of disease severity and persistence. As shown earlier, $35 \%$ did not satisfy ARA criteria after 12 months of follow up. It might, therefore, be expected that the familial risk in the first degree relatives of those cases might differ from the remaining $65 \%$. Small numbers of cases amongst the first degree relatives preclude a definitive answer, but restricting the analyses to only the first degree relatives of those subjects who had 'definite RA' did not alter the findings (table 2).

Analysis was restricted only to those first degree relatives living within the Norwich Health Authority, for logistic reasons. Access to medical records was readily available within the local area and follow up would have been more complex for those who lived outside the area and even outside the country. It is unlikely that this exclusion introduced any bias, as the same rule was applied to the first degree relatives of both cases and controls and, in this moderately stable population, only $10 \%$ of the first degree relatives lived outside the area.

In summary, this study has examined a true population derived sample of cases with a recent onset of inflammatory joint disease. Despite the small numbers, the study has excluded all but a modest degree of familial clustering. This has a number of implications. First, these data support other observations that the specific HLA-DRB1 alleles of the shared epitope are associated more closely with disease persistence/severity than with disease susceptibility. Second, the penetrance of any presumed disease susceptibility alleles is likely to be low, enhancing the difficulties of investigating for genetic linkage. As a consequence, the number of families required for such studies will be extremely large.

1 Lawrence J S. Rheumatoid arthritis-nature or nurture? Ann Rheum Dis 1970; 29: 357-79.

2 Aho K, Koskenvuo M, Tuominen J, Kaprio J. Occurrence of rheumatoid arthritis in a nationwide series of twins. ҰRheumatol 1986; 13: 899-902.

3 Silman A J, MacGregor A J, Thomson W, et al. Twin concordance rates for rheumatoid arthritis: a nationwide study. Br F Rheumatol 1993; 32: 903-7.

4 Rigby A S, Voelm L, Silman A J. Epistatic modeling in rheumatoid arthritis: an application of the Risch theory. Genet Epidemiol 1993; 10: 311-20.

5 Deighton C M, Walker D J, Griffiths I D, Roberts D F. The contribution of HLA to rheumatoid arthritis. Clin Genet 1989; 36: 178-82.

6 Deighton C M, Walker D J. The familial nature of rheumatoid arthritis. Ann Rheum Dis 1991; 50: 62-5.

7 Wordworth P, Bell J. Polygenic susceptibility in rheumatoid ordworth P, Bell J. Polygenic susceptibility 
8 Risch N. Assessing the role of HLA-linked and unlinked determinants of disease. Am $\mathcal{F}$ Hum Genet 1987; 40: determ.

9 Wolfe $\mathrm{F}$, Kleinheksel S M, Khan M A. Prevalence of familial occurrence in patients with rheumatoid arthritis. $\mathrm{Br} \mathcal{F}$ Rheumatol 1988; 27 (suppl II): 150-2.

10 Deighton C M, Wentzel J, Cavanagh G, Roberts D F, Walker D J. Contribution of inherited factors to rheumatoid arthritis. Ann Rheum Dis 1992; 51: 182-5.

11 del Junco D J, Luthra H S, Annegers J F, Worthington J W, Kurland $\mathrm{L}$ T. The familial aggregation of rheumatoid arthritis and its relationship to the HLA-DR4 association. Am f Epidemiol 1984; 119: 813-29.

12 Lawrence J S. The epidemiology and genetics of rheumatoid arthritis. In: Lawrence I S, ed. Population studies and genetics. Rheumatology. Basel, New York: Karger, 1969; genetic.

13 Hellgren L. Inheritance of rheumatoid arthritis. Acta Rheum Scand 1970; 16: 211-6.

14 Symmons D P M, Barrett E $M$, Bankhead C $R$, Scott D G I, Silman A J. The incidence of rheumatoid arthritis in the United Kingdom: results from the Norfolk Arthritis Register. Br $\mathcal{F}$ Rheumatol 1994; 33: 735-9.

15 Arnett F C, Edworthy S M, Bloch D A, et al. The American Rheumatism Association 1987 revised criteria for the classification of rheumatoid arthritis. Arthritis Rheum 1988; 31: 315-24.

16 MacGregor A J, Riste L K, Hazes J M W, Silman A J. Low prevalence of rheumatoid arthritis in black-Caribbeans compared with whites in inner city Manchester. Ann Rheum Dis 1994; 53: 293-7.
17 MacGregor A J, Bamber S, Silman A J. A comparison of the performance of different methods of disease classification for rheumatoid arthritis. Results of an analysis from a nationwide twin study. $\mathcal{F}$ Rheumatol 1994; 21: $1420-6$.

18 Lawrence R C, Hochberg M C, Kelsey J L, McDuffie F C, Medsger T A. Estimates of the prevalence of selected arthritic and musculoskeletal diseases in the United States. I Rheumatol 1989; 16: 427-41.

19 Silman A J, Hochberg M C. Epidemiology of the rheumatic diseases. Oxford: Oxford University Press, 1994.

20 De Jongh B M, van Romunde L K J, Valkenburg H A, De Lange G G. Epidemiological study of HLA and GM in rheumatoid arthritis and related symptoms in an open Dutch population. Ann Rheum Dis 1984; 43: 613-9.

21 Thomson W, Pepper L, Payton A, et al. Absence of an association between HLA-DRB $1^{\star} 04$ and rheumatoid arthritis in newly diagnosed cases from the community. Ann Rheum Dis 1993; 52: 539-41.

22 Salmon M, Wordsworth P, Emery P, Tunn E, Bacon P A, Bell J I. The association of HLA DRB alleles with selflimiting and persistent forms of early symmetrical polyarthritis. Br f Rheumatol 1993; 32: 628-30.

23 Wagener D K, Sacks J M, LaPorte R E, MacGregor J M. The Pittsburgh study of insulin-dependent diabetes mellitus: Risk for diabetes among relatives of IDDM. Diabetes 1982; 31: 136-44.

24 Kuwert E K. Genetic aspects of multiple sclerosis with special regard to histocompatibility determinants. Acta Neurol Scand 1977; 55 (suppl):23-42. 